\title{
Conceptos básicos para la solicitud e interpretación de analíticas en podología
}

Basic concepts for the request and interpretation of blood tests in podiatry

Óscar Álvarez-Calderón Iglesias

Servicio de ORL - Hospital de Ourense. Universidade da Coruña. A Coruña. España

Palabras clave:

Analítica, podología, hemograma, coagulación, bioquímica, preoperatorio

\section{Resumen}

La analítica sanguínea representa una prueba complementaria utilizada de manera generalizada en medicina para el estudio de la homeostasis corporal. Sus aplicaciones son numerosas, y en cada disciplina o especialidad existen parámetros específicos que se pueden solicitar como ayuda al diagnóstico de una patología, para monitorizar su actividad, así como para evaluar la utilidad de los fármacos utilizados. Asimismo, la analítica es utilizada de manera casi rutinaria, junto con otros test, en el periodo prequirúrgico. La solicitud de pruebas analíticas indiscriminadas no está justificada desde ningún punto de vista, por lo que se intentará hacer énfasis en la idea de peticiones dirigidas tras una sospecha clínica fundada. El podólogo, dentro de sus competencias, debe saber cómo y cuándo solicitar una analítica, y por tanto tiene la responsabilidad de saber cómo interpretarla de manera adecuada.

Abstract

Blood tests request represents a group of complementary tests widely used in medicine for the study of body homeostasis. Its applications are numerous, and each discipline or speciality make use of specific parameters or biomarkers that can be helpful in order to make the diagnosis, or monitor a specific disease, as well as, evaluate the usefulness of certain drugs. Moreover, blood tests are commonly used in preoperative period. The request for indiscriminate blood tests, is completely unjustified. The idea of focused blood tests should be taken into account. Podiatrists within their profesional competences, must have the knowledge of when and how request blood tests and therefore the responsibility of its interpretation. 


\section{INTRODUCCIÓN}

En la medicina clásica ${ }^{1}$ los diagnósticos se basaban en una buena anamnesis, así como en una buena exploración física. Con el paso del tiempo, la medicina contemporánea se ha ido apoyando cada vez más en pruebas complementarias de diferentes especialidades, como el radiodiagnóstico, el laboratorio de análisis clínicos o de microbiología, anatomía patológica, neurofisiología, etc. Los análisis de sangre se han venido utilizando desde hace décadas como apoyo al diagnóstico o para comprobar la eficacia de diferentes tratamientos, entre otras funciones.

En el campo de la podología, poco se ha publicado en la literatura científica de la especialidad en los últimos años acerca de este tema ${ }^{2-7}$. Las aplicaciones de las analíticas en el campo de la podología son múltiples, como veremos más adelante. Además de para el apoyo diagnóstico, la analítica deberá ser utilizada o solicitada para conocer el estado general del paciente de cara al establecimiento de determinados tratamientos farmacológicos, o al sometimiento a intervenciones quirúrgicas o invasivas. Es de sobra conocida la repercusión y manifestaciones de un gran número de enfermedades sistémicas en la piel, así como en los anejos cutáneos, tanto de los miembros inferiores como de los pies. De manera fundamental (y no exclusiva), los podólogos hemos venido utilizando la analítica de sangre para el control y manejo del paciente quirúrgico, el control de las enzimas hepáticas en pacientes a tratamiento con antifúngicos orales, o el diagnóstico y control del paciente diabético o reumático, entre otras. Por supuesto, la integración del podólogo dentro de equipos multidisciplinares de distintos ámbitos abre un abanico enorme de funciones diagnósticas y terapéuticas que se pueden ayudar de los exámenes de laboratorio.

No es el objetivo de este artículo profundizar en los aspectos fisiopatológicos de las patologías que se describirán a continuación. Se remite al lector que desee información específica y detallada a los grandes tratados de patología ${ }^{8}$ y medicina interna ${ }^{9,10}$, así como a las referencias bibliográficas específicas utilizadas en el desarrollo de este texto.

\section{Generalidades de la sangre}

La sangre es un tejido líquido compuesto por el plasma y las células sanguíneas (hematíes, leucocitos y plaquetas). El plasma constituye entre el 55 y el $60 \%$ del volumen sanguíneo y su componente principal es el agua, aunque también contiene diferentes sustancias como iones, proteínas, gases, grasas o vitaminas.

La producción de células sanguíneas se denomina hematopoyesis, y en el adulto se lleva a cabo fundamentalmente en la médula ósea. Sin ánimo de profundizar en el tema, recordemos que existen unas células con capacidad de proliferación y diferenciación que darán lugar a una célula troncal hema- topoyética, que a su vez dará lugar a un progenitor linfoide que dará lugar a los linfocitos, y a un progenitor mieloide del que saldrán los eritrocitos, megacariocitos (precursores de las plaquetas), macrófagos y granulocitos. Conocer las distintas fases de maduración de cada célula es importante por la implicación clínica que pueda tener la presencia de células inmaduras en sangre.

Para la obtención y posterior análisis de sangre, generalmente utilizamos sangre venosa periférica obtenida por venopunción. La sangre es separada en sus diferentes fracciones a través de un proceso de centrifugación del que se obtendrán distintas interfases. Así se obtiene un sobrenadante superior, que corresponde al plasma, una fracción intermedia que corresponde a los leucocitos, y una última fracción, la más profunda, que corresponde a los eritrocitos. Mediante otro proceso se puede obtener también el suero sanguíneo para su análisis, que no es más que el plasma sin las proteínas que intervienen en la coagulación.

\section{HEMOGRAMA}

El hemograma es el análisis de sangre periférica en el que se realizan las mediciones, en números absolutos o porcentajes, de las células sanguíneas ${ }^{11}$. Para su análisis se utiliza sangre total anticoagulada con EDTA (ácido etilendiaminotetraacético) tripotásico. Las mediciones se realizarán mediante diferentes métodos como impedancia, difracción de luz o láser. En la Tabla I se indican los valores de referencia para cada parámetro evaluado en el hemograma. En la Tabla II se indican los puntos clave de este apartado.

\section{Serie roja}

La serie roja o eritrocitaria proporciona el recuento de hematíes, de hemoglobina, el hematocrito y los índices eritrocitarios, como son el volumen corpuscular medio (VCM), la hemoglobina corpuscular media (HCM), la concentración de hemoglobina corpuscular media ( $\mathrm{CHCM}$ ) y la amplitud de distribución eritrocitaria (ADE).

Los eritrocitos o hematíes constituyen más del $90 \%$ de las células sanguíneas. Antes de su maduración, la célula pasa por diferentes etapas (hemocitoblasto, proeritroblasto, eritroblasto, normoblasto y reticulocito) hasta convertirse en eritrocito maduro.

La hemoglobina es una proteína presente en el eritrocito, cuya función principal es la de transportar el oxígeno en la sangre y recoger el dióxido de carbono. En su estructura contiene un átomo de hierro. La concentración normal de hemoglobina en sangre varía en función del sexo, de la edad o de la situación geográfica.

El hematocrito representa la relación existente entre el volumen que ocupan los hematíes y el correspondiente a la sangre total, expresado en porcentaje. El valor depende tanto 
Tabla I. Valores de referencia del hemograma

\begin{tabular}{|c|c|c|}
\hline \multicolumn{3}{|c|}{ Hemograma } \\
\hline & Unidades & Valores de referencia \\
\hline Leucocitos & $10^{\wedge} 3 / \mu 1$ & [3.91-8.77] \\
\hline Neutrófilos & $\%$ & {$[42.0-75.0]$} \\
\hline Linfocitos & $\%$ & {$[20.0-50.0]$} \\
\hline Monocitos & $\%$ & {$[2.0-12.0]$} \\
\hline Eosinófilos & $\%$ & {$[2.0-5.0]$} \\
\hline Basófilos & $\%$ & {$[0.01-2.0]$} \\
\hline Granulocitos inmaduros & $\%$ & {$[0.0-2.0]$} \\
\hline Hematíes & $10^{\wedge} 6 / \mu 1$ & {$[4.7-6.1]$} \\
\hline Reticulocitos & $10^{\wedge} 3 / \mu 1$ & [30-70] \\
\hline \multirow{2}{*}{ Hemoglobina } & \multirow{2}{*}{$\mathrm{g} / \mathrm{dl}$} & [14.0-18.0] Hombres \\
\hline & & [12.0-16.0] Mujeres \\
\hline \multirow{2}{*}{ Hematocrito } & \multirow{2}{*}{$\%$} & [40.0-54.0] Hombres \\
\hline & & [37.0-47.0] Mujeres \\
\hline VCM & $\mathrm{fl}$ & [80.0-93.6] \\
\hline $\mathrm{HCM}$ & $\mathrm{pg}$ & {$[27.0-32.0]$} \\
\hline $\mathrm{CHCM}$ & $\mathrm{g} / \mathrm{dl}$ & {$[32.0-36.0]$} \\
\hline ADE & $\%$ & {$[12.0-15.0]$} \\
\hline Plaquetas & $10^{\wedge} 3 / \mu l$ & [135.0-304.0] \\
\hline Volumen plaquetar medio & $\mathrm{fl}$ & {$[7.0-11.0]$} \\
\hline VSG & $\mathrm{mm}$ & {$[0.0-15.0]$} \\
\hline
\end{tabular}

del número de hematíes, de su forma y tamaño, como del volumen plasmático.

Los índices eritrocitarios son calculados en función de las cifras del hematocrito, de la hemoglobina y del número de hematíes. EI VCM corresponde al volumen promedio de cada eritrocito. Permite clasificar a las anemias en microcíticas, normocíticas o macrocíticas. La HCM representa la carga o peso medio de la hemoglobina de cada eritrocito. Permite clasificar a las anemias en hipocrómicas, normocrómicas e hipercrómicas. La CHCM representa la concentración media de la hemoglobina de cada eritrocito. Sus valores disminuyen en las anemias microcíticas, se encuentra en rango en las anemias macrocíticas, y se eleva en enfermedades como la anemia de células falciformes o la esferocitosis hereditaria, entre otras. El ADE cuantifica la variación en el volumen de los eritrocitos.

La anemia se define clásicamente como una disminución del número de hematíes circulantes, aunque en la práctica clínica se utilizan principalmente las cifras de hemoglobina para su diagnóstico ${ }^{12-14}$. Las manifestaciones clínicas dependen de si la instauración es brusca o lenta. Típicamente la anemia se presenta con signos y síntomas inespecíficos, como son palidez cutáneo-mucosa, cansancio, fragilidad ungueal y capilar, disnea, taquipnea, cefalea, acúfenos, irritabilidad, vértigos, etc. Cuando la instauración es lenta, los pacientes pueden estar asintomáticos debido a un proceso de "habituación".

Dependiendo de la clasificación inicial de la anemia en base a los índices eritrocitarios y de la sospecha clínica, podrá ser necesario ampliar el estudio de laboratorio con otras determinaciones (reticulocitos, hierro, vitamina $\mathrm{B}_{12}$, ácido fólico, bilirrubina, LDH, haptoglobina, función hepática, función tiroidea o frotis de sangre periférica).

\section{Tabla II. Puntos clave del hemograma}

- El hemograma evalúa la serie roja, blanca y plaquetar

- En la práctica clínica, la anemia se evalúa a través de los niveles de hemoglobina

- La anemia ferropénica es generalmente microcítica e hipocrómica. En la analítica se expresa con valores de hierro disminuidos, ferritina disminuida, transferrina elevada y saturación de transferrina disminuida

- La anemia de procesos crónicos es generalmente normocítica y normocrómica. En la analítica veremos hierro sérico disminuido, transferrina baja, ferritina normal o elevada. Es típica en enfermedades como la artritis reumatoide

- Las anemias relacionadas con el consumo de alcohol y con déficits de vitamina $\mathrm{B}_{12}$ y ácido fólico son macrocíticas

- La primera sospecha ante un paciente con leucocitosis y neutrofilia será un proceso infeccioso bacteriano o inflamatorio severo

- La neutrofilia es frecuente en pacientes a tratamiento con glucocorticoides sistémicos

- La neutropenia predispone a padecer infecciones y en todos los casos debe ser estudiada para descartar patología de base

- Sospecharemos un déficit plaquetario en pacientes con historia de sangrado espontáneo, petequias, epistaxis, sangrado gingival o menorragia

- Valores menores de 70.000 plaquetas condicionan la realización de un tratamiento quirúrgico

- Los fármacos antiagregantes plaquetarios no se monitorizan con pruebas de laboratorio de rutina, y no modifican los parámetros de coagulación. 
Las anemias microcíticas, $\mathrm{VCM}<80 \mathrm{fl}$, se asocian generalmente a hipocromía. La causa más frecuente en nuestro medio es la ferropenia ${ }^{15}$.

En las anemias normocíticas, el VCM se encuentra entre [80-100] fl. La anemia de procesos $\operatorname{crónicos}^{16}$ es la más frecuente de las normocíticas, y la segunda más frecuente en nuestro medio tras la ferropénica. Causas frecuentes de este tipo de anemia son las infecciones crónicas (o algunas agudas), la insuficiencia renal o hepática, enfermedades endocrinas, enfermedades reumáticas o neoplasias.

En las anemias macrocíticas nos encontramos con un $V C M>100 \mathrm{fl}$. Este tamaño aumentado del eritrocito puede verse acompañado de la presencia de megalobastos (eritrocitos inmaduros con núcleo voluminoso). Las anemias macrocíticas megaloblásticas ${ }^{17}$ son generalmente debidas a un déficit en vitamina $B_{12} y$ de ácido fólico. Las causas de déficit de vitamina $B_{12}$ son la ingesta insuficiente con la dieta, la malabsorción (anemia perniciosa, pacientes gastrectomizados) o algunos fármacos. Las causas de déficit de ácido fólico son el aporte insuficiente por la dieta, el consumo elevado de alcohol, embarazo, lactancia, malabsorción o algunos fármacos. Las anemias macrocíticas no megaloblásticas generalmente son debidas a un consumo excesivo de alcohol, o a alteraciones en la médula ósea como la aplasia o la mielodisplasia.

La poliglobulia, hallazgo en nuestro medio mucho menos frecuente que la anemia, se define como el aumento total de la masa total de eritrocitos (> al $120 \%$ ) de la que corresponde a un individuo por superficie corporal y sexo. Las cifras de hemoglobina se verán aumentadas.

\section{Serie blanca}

Los leucocitos son las células encargadas de la defensa frente a distintos patógenos externos. Morfológicamente se dividen en granulocitos o polimorfonucleares (neutrófilos, basófilos y eosinófilos) y en agranulocitos o mononucleares (monocitos y linfocitos). Los granulocitos y los monocitos son los principales efectores de la inmunidad innata, ejerciendo su función a través de la fagocitosis. Los linfocitos son las principales células efectoras de la inmunidad adaptativa e incluyen a las células B y T. Los linfocitos B producen anticuerpos específicos y los linfocitos T destruyen a las células que reconocen como extrañas y aquellas infectadas por virus.

Los neutrófilos, antes de completar su maduración (célula segmentada), pasan por diferentes estadios (mieloblasto, promielocito, mielocito, metamielocito y célula en banda o cayado).

Al número total de leucocitos se le denomina recuento absoluto leucocitario. Al recuento de cada subtipo celular se le denomina recuento diferencial leucocitario. El recuento diferencial se puede expresar en número o en porcentaje del total de leucocitos. Al recuento absoluto de leucocitos más el recuento porcentual de cada subtipo celular es lo que se conoce como fórmula leucocitaria.
A la hora de interpretar un porcentaje de neutrófilos, por ejemplo, hay que tener siempre en cuenta el recuento absoluto leucocitario, ya que un paciente con un $50 \%$ de neutrófilos para un total de 8000 leucocitos estará dentro del rango de normalidad, pero un paciente con un $50 \%$ de neutrófilos con un recuento total de 1000 leucocitos estará en un estado de neutropenia severa, lo que corresponde a una urgencia médica.

Ante un evento de causa infecciosa, generalmente (no siempre), el número total de células blancas tenderá a aumentar, y eso es lo que se conoce como leucocitosis, y de manera específica aumentará también el subtipo celular en función del germen causante de la infección. Por lo tanto, en el contexto de una infección bacteriana aumentará el número de neutrófilos, ante una infección vírica sistémica nos podemos encontrar con un estado de linfocitosis y monocitosis, y en casos de infecciones fúngicas severas tiende a aumentar el recuento de monocitos.

En relación con el aumento de polimorfonucleares, nos podemos encontrar con "desviación izquierda", que no es más que la aparición de células "en banda o cayados" en exceso en sangre periférica. Estas células son neutrófilos "jóvenes" o inmaduros que la médula ósea produce en el contexto de un proceso infeccioso y que son detectados en sangre. Este hecho nos ha de poner en alerta de que existe alguna razón (infecciosa, mieloproliferativa...) por la que se están produciendo nuevos neutrófilos.

Generalmente en el contexto de reacciones o enfermedades alérgicas o parasitosis tiende a aumentar el recuento de basófilos y eosinófilos. En relación con las enfermedades alérgicas, y aunque no forma parte del hemograma, los niveles séricos de lgE total generalmente se ven aumentados. Ante la sospecha de enfermedad alérgica se pueden solicitar lgE específicas ${ }^{18}$ para diferentes alérgenos, que nos pueden apoyar en el diagnóstico de estas patologías.

Otras causas de aparición de leucocitosis son la utilización de fármacos (corticoides sistémicos, litio, ácido transretinoico, catecolaminas, factores de crecimiento mieloide), situaciones de estrés, el tabaquismo crónico, cuadros inflamatorios crónicos no infecciosos o deshidratación, entre otros. Un proceso infeccioso severo podría llegar a elevar los leucocitos hasta 20-30.000 células/ml. Ante recuentos superiores se debería descartar un proceso mieloproliferativo, como por ejemplo una leucemia.

En cuanto a las citopenias (disminución en el recuento celular), existen diferentes cuadros clínicos que podrían justificarlas. La neutropenia (que generalmente acompaña a una leucopenia), es la disminución absoluta del número de neutrófilos, siendo la causa más frecuente la inducida por fármacos (agentes quimioterápicos, antiepilépticos...).

\section{Serie plaquetar}

La serie plaquetar se evalúa fundamentalmente a través del recuento de plaquetas. Existen otros parámetros, como 
el volumen plaquetar medio, el plaquetocrito, el índice de dispersión de plaquetas o la morfología plaquetar, los cuales no se determinan de manera rutinaria.

Las plaquetas son los elementos formes más pequeños de la sangre y son las responsables de la primera fase de la hemostasia. De manera resumida, cuando existe un daño en el endotelio vascular, va a haber una exposición de fibras de colágeno. A partir de aquí entrarán en juego una serie de sustancias y moléculas que, de manera combinada, van a favorecer la activación, adherencia y agregación plaquetaria, terminando el proceso con la formación del trombo primario.

Cualquier disfunción en este mecanismo puede dar lugar a cuadros clínicos que cursan con un déficit en la hemostasia primaria $^{19}$. Diferentes enfermedades pueden provocar una disfunción plaquetaria, por ejemplo la enfermedad de Von Willebrand, la púrpura trombocitopénica, la coagulación intravascular diseminada o el síndrome hemolítico urémico, entre otros. El diagnóstico inicial de estas patologías se hace en base a una buena historia clínica y exploración física. Las manifestaciones típicas son las hemorragias espontáneas cutáneas o mucosas, hemorragias en el periodo postoperatorio inmediato, hemorragias gingivales, epistaxis, excesivo sangrado menstrual, sangrado con el afeitado, o la aparición de signos cutáneos como lesiones purpúricas, petequias o equimosis.

El déficit plaquetario se denomina trombopenia, trombocitopenia o plaquetopenia, y se define por un recuento de plaquetas menor al límite de referencia de lo establecido como normal. Hablaremos de trombocitopenia leve cuando nos encontremos con valores hasta $100 \times 10^{\wedge} 3$ plaquetas $/ \mu \mathrm{l}$, moderada con valores entre [100-50] x 10^3 plaquetas $/ \mu$ l y severa con valores menores a $50 \times 10^{\wedge} 3$ plaquetas $/ \mu$ l. No existe una correlación directa entre el número de plaquetas y el riesgo de sangrado, pero sí que se establece que con cifras entre [100-50] x 10^3 plaquetas $/ \mu \mathrm{l}$, existe riesgo de sangrado en relación con las intervenciones quirúrgicas. Con cifras inferiores a $50 \times 10^{\wedge} 3$ plaquetas $/ \mu$ l aumenta el riesgo de hemorragias espontáneas.

El caso contrario se denomina trombocitosis, y puede condicionar un estado de hiperagregación plaquetaria que favorezca eventos tromboembólicos.

La hemostasia primaria se valora en una analítica, principalmente mediante el recuento de plaquetas, aunque existen otras determinaciones que también pueden ser utilizados para comprobar la función trombocitaria ${ }^{20,21}$. Aquellos pacientes en tratamiento con fármacos antiagregantes plaquetarios, no precisarán prueba específica alguna para evaluar la función trombocitaria de cara a la realización de una intervención quirúrgica.

\section{Velocidad de sedimentación globular}

La velocidad de sedimentación globular (VSG) se obtiene midiendo la velocidad de sedimentación de los eritrocitos en un periodo determinado de tiempo. Constituye una forma de medición indirecta de la concentración de reactantes de fase aguda (RFA). En un estado de inflamación, la presencia de concentraciones elevadas en plasma de RFA favorece la agregación eritrocitaria y, por lo tanto, una mayor velocidad de sedimentación. Representa un parámetro sensible a los procesos inflamatorios, infecciosos o neoplásicos. Puede utilizarse como método de screening o como seguimiento de cuadros de causa inflamatoria. La VSG, de manera característica, se eleva en enfermedades como la polimialgia reumática o la arteritis de la temporal.

\section{BIOQUÍMICA}

A través del estudio bioquímico de la sangre se pretende medir los niveles de parámetros de diferente naturaleza, que nos den información acerca de la función de diferentes órganos, como el riñón o el hígado, además de obtener niveles de diferentes sustancias como electrolitos ( $\mathrm{Na}, \mathrm{K}, \mathrm{P}, \mathrm{Mg}, \mathrm{Ca}$ ), vitaminas $\left(\mathrm{B}_{12}\right.$, ácido fólico), proteínas (albúmina, proteína $\mathrm{C}$ reactiva, factor reumatoideo, etc.), marcadores tumorales, metabolitos del hierro o de los lípidos u hormonas (TSH, T3, T4, etc.), entre otras determinaciones. Para su estudio se utilizan muestras como sangre, con o sin anticoagulante, o suero, que serán analizados mediante diferentes métodos, como son la electroluminiscencia, la cromatografía, la espectrofotometría o el radioinmunoensayo, entre otros muchos. Se ha descrito la implicación de diferentes condiciones, así como determinados déficits orgánicos con distintas manifestaciones clínicas de interés para el podólogo ${ }^{22-25}$, por lo que el estudio bioquímico puede serle de gran utilidad en el apoyo diagnóstico. En la Tabla III se indican los valores de referencia de los principales parámetros estudiados en la bioquímica de interés en este artículo. En la Tabla IV se indican los puntos clave de este apartado.

\section{Glucosa en sangre}

La glucemia representa el nivel de glucosa en sangre expresado en $\mathrm{mg} / \mathrm{dl}$. Cuando existe una disminución de su nivel hablaremos de hipoglucemia, y cuando nos encontramos con aumentos de su nivel, hablaremos de manera general de hiperglucemia. Dentro de los criterios diagnósticos de la diabetes $^{26}$, la American Diabetes Association establece que niveles de glucemia > de $126 \mathrm{mg} / \mathrm{dl}$ con el individuo en ayunas, o una concentración > o igual a 200 mg/dl después de una sobrecarga oral de glucosa, o en un paciente con sintomatología típica de la enfermedad, son diagnósticos de diabetes mellitus. El valor de la determinación de los niveles de glucemia es de utilidad limitada para controlar los niveles de glucosa en sangre, para ello utilizaremos la hemoglobina glicosilada. Son de sobra conocidas las implicaciones clínicas de la hipoglucemia, así como las potenciales complicaciones sobre órganos diana de la hiperglucemia mantenida. 
Tabla III. Valores de referencia de bioquímica

\begin{tabular}{|c|c|c|}
\hline & Unidades & Valores de referencia \\
\hline Glucosa & $\mathrm{mg} / \mathrm{dl}$ & [80.0-115.0] \\
\hline $\mathrm{HAb} 1 \mathrm{c}$ & $\%$ & {$[4.0-6.0]$} \\
\hline Urea & $\mathrm{mg} / \mathrm{dl}$ & [19.0-47.0] \\
\hline Creatinina & $\mathrm{mg} / \mathrm{dl}$ & {$[0.5-1.5]$} \\
\hline $\begin{array}{l}\text { TFG (CKD-EPI, } \\
\text { 2011) }\end{array}$ & $\mathrm{ml} / \mathrm{min} / 1,73 \mathrm{~m}^{2}$ & $\begin{array}{c}<60 \text { insuficiencia renal } \\
\text { crónica }\end{array}$ \\
\hline Proteínas totales & $\mathrm{g} / \mathrm{dl}$ & [6.4-8.3] \\
\hline Albúmina & $\mathrm{g} / \mathrm{dl}$ & {$[3.5-5.2]$} \\
\hline Vitamina $B_{12}$ & $\mathrm{pg} / \mathrm{ml}$ & [180.0-914.0] \\
\hline Ácido fólico & $\mathrm{ng} / \mathrm{ml}$ & {$[3.1-20.0]$} \\
\hline Sodio & $\mathrm{mmol} / \mathrm{l}$ & [136.0-147.0] \\
\hline Potasio & $\mathrm{mmol} / \mathrm{l}$ & {$[3.5-5.1]$} \\
\hline Calcio & $\mathrm{mmol} / \mathrm{l}$ & {$[8.8-10.2]$} \\
\hline Fosfato & $\mathrm{mg} / \mathrm{dl}$ & [2.6-4.6] \\
\hline Magnesio & $\mathrm{mg} / \mathrm{dl}$ & {$[1.6-2.4]$} \\
\hline ASAT/GOT & $U / I$ & {$[5.0-32.0]$} \\
\hline ALAT/GPT & $U / I$ & {$[5.0-33.0]$} \\
\hline GGT & $U / I$ & {$[5.0-40.0]$} \\
\hline FA & $U / I$ & [35.0-104.0] \\
\hline LDH & $\mathrm{U} / \mathrm{I}$ & [240.0-480.0] \\
\hline Bilirrubina total & $\mathrm{mg} / \mathrm{dl}$ & {$[0.1-1.2]$} \\
\hline $\mathrm{Fe}$ & $\mu \mathrm{g} / \mathrm{dl}$ & [59.0-158.0] \\
\hline Ferritina & $\mathrm{ng} / \mathrm{ml}$ & [30.0-400.0] \\
\hline Transferrina & $\mathrm{mg} / \mathrm{dl}$ & [200.0-360.0] \\
\hline $\begin{array}{l}\text { Saturación de } \\
\text { transferrina }\end{array}$ & $\%$ & {$[16.0-45.0]$} \\
\hline TSH & $\mu \mathrm{UI} / \mathrm{ml}$ & {$[0.34-5.35]$} \\
\hline T4 & $\mathrm{pg} / \mathrm{ml}$ & [0.93-1.70] \\
\hline T3 & $\mathrm{pg} / \mathrm{ml}$ & [2.57-4.43] \\
\hline Urato & $\mathrm{mg} / \mathrm{dl}$ & [3.4-7.0] \\
\hline PCR & $\mathrm{mg} / \mathrm{dl}$ & {$[0.1-0.5]$} \\
\hline FR & $\mathrm{UI} / \mathrm{ml}$ & [2.0-14.0] \\
\hline ANTI-CCP & $\mathrm{U} / \mathrm{ml}$ & [0.1-6.3] \\
\hline CK & $U / I$ & $\begin{array}{c}\text { [32-294] Hombres } \\
{[33-211] \text { Mujeres }}\end{array}$ \\
\hline
\end{tabular}

La hemoglobina glicosilada, $\mathrm{HbA} 1 \mathrm{c}$, representa un parámetro útil tanto para el diagnóstico de la diabetes mellitus (niveles > o iguales a $6.5 \%{ }^{26}$ se consideran diagnósticos de la enfermedad), como para el seguimiento del nivel de glucosa en el tiempo. Se ha establecido que los niveles de $\mathrm{HbA} 1 \mathrm{c}$ muestran de una manera fiable los niveles de glucosa en sangre en los últimos tres meses. Su titulación de cara a monitorizar los niveles de glucosa en sangre, por panto, representa una forma más exacta que la medición tradicio- nal de la glucemia en sangre ${ }^{27}$. Aunque el nivel de HbA1c óptimo debe ser individualizado en función de las características de cada paciente, un objetivo razonable es mantener niveles por debajo del $7 \%$. Se acepta un nivel de hasta $8 \%$ en aquellos pacientes de más edad, con más comorbilidades y con menor expectativa de vida. Las guías clínicas ${ }^{28}$ recomiendan su titulación cada 3-6 meses hasta que la cifra esté controlada.

\section{Función renal}

De manera clásica, la función renal ha sido controlada a través de la tasa de filtrado glomerular (TFG), la cual equivale a la suma de las tasas de función glomerular de todas las nefronas. El valor normal dependerá de la edad, el género, la superficie corporal y la raza del individuo. La forma más frecuente de calcularla es a través de las ecuaciones de estimación basadas en la creatinina sérica ${ }^{29}$.

La creatinina es un producto del metabolismo del músculo esquelético que se libera de manera constante a la sangre y que es filtrada por los riñones. Representa un parámetro útil para valorar la función renal, aunque hay que tener en cuenta que su valor varía dependiendo de la masa muscular de los individuos. Un aumento de los niveles sanguíneos de creatinina indicará alteraciones en la función glomerular.

La urea es un producto final del metabolismo de las proteínas, que se genera en el hígado y es transportada por la sangre hasta los riñones donde se excreta a través de la orina. El nitrógeno ureico en sangre o BUN (Blood Urea Nitrogen) es otro parámetro utilizado para la medición de la función renal, y representa la cantidad de nitrógeno circulando a través de la sangre en forma de urea. Un aumento de la uremia, por tanto, traducirá una alteración en la función renal.

La insuficiencia renal es una enfermedad que puede manifestarse de manera aguda o crónica. La insuficiencia renal aguda $^{30}$, además de a través de otros parámetros y signos clínicos, en la analítica se manifiesta con elevaciones séricas en la urea y/o creatinina. La cronicidad se establece por un descenso en la TFG $<60 \mathrm{~mL} / \mathrm{min} / 1.73 \mathrm{~m}^{2}{ }^{31}$ de más de tres meses de evolución. Las complicaciones más frecuentes del fallo renal son las alteraciones en el balance hidro-electrolítico, hiperpotasemia, acidosis metabólica o alteraciones hormonales. Se ha establecido relación entre la insuficiencia renal a tratamiento con hemodiálisis y las diferentes alteraciones dermatológicas con repercusión en partes blandas y en los pies ${ }^{32}$.

\section{Proteínas y vitaminas}

Las proteínas plasmáticas en mayor medida se sintetizan a nivel hepático. La hipoproteinemia generalmente traduce déficits nutricionales, aunque también es típico en las quemaduras severas, hemorragias, alteraciones renales o en sín- 
Tabla IV. Puntos clave de la bioquímica

- La HbA1c es el mejor parámetro analítico para monitorizar los valores de glucemia

- La TFG se establece en base a la creatinina sérica y se calcula automáticamente en el laboratorio a partir de unas ecuaciones estandarizadas que tienen en cuenta diferentes parámetros

- La creatinina y la urea son dos buenos parámetros para valorar la función renal

- Los valores de normalidad de creatinina varían en función de la masa muscular del individuo

- La hipoalbuminemia se relaciona con la aparición de complicaciones postquirúrgicas y lesiones ungueales (líneas de Muehrcke)

- Los déficits de vitamina $B_{12}$ se relacionan con alteraciones neuropáticas, del equilibrio y de la marcha

- Las alteraciones iónicas se relacionan con alteraciones en la conducción nerviosa, así como en la contractilidad muscular

- Se ha relacionado la hiponatremia con alteraciones en la marcha

- La hiperpotasemia puede provocar arritmias severas

- La hipocalcemia es frecuente en cuadros de hiperreflexia

- La elevación de las transaminasas ALAT/GPT y ASAT/GOT son indicativas de daño en el hepatocito

- En pacientes a tratamiento continuado con antifúngicos orales se recomienda la monitorización de la función hepática

- En individuos con consumo excesivo de alcohol, se verán aumentadas las transaminasas, en mayor proporción la ASAT/GOT además de la GGT

- Es recomendable monitorizar la función hepática en pacientes con ingesta excesiva de alcohol previo a una cirugía

- En estados de ferropenia generalmente los valores de Fe en sangre disminuyen, aumentan los de transferrina, desciende la saturación de transferrina y descienden los niveles de ferritina

- Se relaciona el déficit de Fe con la coiloniquia

- En el hipertiroidismo los niveles de TSH estarán disminuidos y en el hipotiroidismo los niveles de TSH estarán normales, disminuidos o aumentados

- Tanto el hiper como el hipotiroidismo se relacionan con alteraciones cutáneas y en las uñas

- Cifras elevadas de urato en sangre no son diagnósticas de gota

- En un ataque agudo de gota podemos encontrarnos leucocitosis con neutrofilia, aumento de los RFA, y los niveles de urato variables

- Los RFA en general son proteínas de síntesis hepática que se elevan ante un evento inflamatorio o infeccioso

- Solo se recomienda la solicitud de FR en pacientes con alta sospecha clínica de AR

- El valor predictivo positivo del FR es alto en pacientes con sintomatología típica de AR o síndrome de Sjögren

- Los anti-CCP son marcadores muy específicos pero poco sensibles para la AR. No se recomiendan como cribado

TFG: tasa de filtración glomerular. HbA1C: hemoglobina glicosilada; RFA: reactantes de fase aguda. FR: factor reumatoide. Anti-CCP: antipéptidos citrulinados cíclicos. AR: artritis reumatoide. PCR: proteína C reactiva.

dromes de mala absorción. Por el contrario, los estados de hiperproteinemia son típicos generalmente de la deshidratación severa, y deberíamos siempre descartar enfermedades como el mieloma múltiple.

La albúmina es una proteína de síntesis hepática, siendo la proteína más importante y abundante en el plasma. Su función principal es la de regular el volumen sanguíneo. También sirve como transportadora de sustancias insolubles en el plasma. La hipoalbuminemia se manifiesta mediante síntomas como molestias a nivel gastrointestinal, o aparición de edemas periféricos. Además, se ha relacionado con un aumento del número de complicaciones postquirúrgicas ${ }^{33,34}$, un aumento del tiempo de estancia hospitalaria e incluso con un aumento de la tasa de mortalidad en pacientes sometidos a intervenciones quirúrgicas con niveles bajos de proteínas. Por ello, se hace necesario vigilar los valores de albúmina en pacientes con déficits nutricionales que van a ser sometidos a cirugía. Se ha descrito, asimismo, la hipoalbuminemia como una posible causa de alteraciones en las uñas ${ }^{35,36}$.

Podemos estudiar también niveles de vitaminas, como la $\mathrm{B}_{12} \mathrm{O}$ el ácido fólico. El déficit de ambas vitaminas, además de con la anemia, se relaciona con aparición de sarcopenia, 
neuropatía, alteraciones en el equilibrio e incluso con alteraciones en la marcha ${ }^{37-39}$.

\section{Iones/Electrolitos}

Para conseguir una correcta homeostasis corporal es fundamental que exista un equilibrio hidroelectrolítico adecuado. Los iones, principalmente el sodio y el potasio, además del calcio, el magnesio, el fósforo y el cloro, son los encargados de ello. Los iones se encuentran implicados en el desarrollo del potencial de acción ${ }^{40}$, por lo tanto son fundamentales para la creación del impulso y de la transmisión neuromuscular, entre otras acciones. Las alteraciones electrolíticas pueden llegar a ser una causa importante de morbimortalidad.

Un estado de hipernatremia, entre otros síntomas, puede producir síntomas como debilidad, irritabilidad, aparición de edemas e incluso convulsiones hasta llegar al estado de coma. La hiponatremia, por su parte, puede ocasionar estados de debilidad generalizada, cefalea, favorecer el desarrollo de osteoporosis y trastornos en la marcha con un riesgo aumentado de caídas ${ }^{41}$.

La hipopotasemia generalmente se produce por un aumento en la pérdida de potasio. Esto ocurre en cuadros de diarrea severa, vómitos, utilización de laxantes, aumento de la sudoración, efecto farmacológico, patología maligna gastro-intestinal, tumores de estirpe endocrina o incluso síndromes de causa genética, como son el Gitleman o el Bartter. Este déficit iónico puede manifestarse con cuadros de mialgias, debilidad muscular, fatiga, calambres, estreñimiento, alteraciones cardiológicas, etc. La hiperpotasemia típicamente cursa con malestar general, debilidad muscular, náuseas y vómitos, parestesias, así como aparición de arritmias severas, que pueden llegar a comprometer la vida del paciente.

El calcio se distribuye en diferentes compartimentos del organismo, siendo el más importante el óseo. La mayor importancia para el organismo es que el calcio es el principal componente mineral del hueso. Además de esta función estructural, su importancia radica en su implicación en procesos como son la excitabilidad neuromuscular, en diferentes reacciones enzimáticas, así como en la cascada de la coagulación, entre otras. La hipercalcemia puede provocar fatiga muscular o mialgias, dolores óseos, alteraciones renales y gastrointestinales, así como alteraciones a nivel cardiovascular. La hipocalcemia puede manifestarse con la aparición de parestesias, espasmos, hiperreflexia e incluso tetania y convulsiones.

La mayor parte del magnesio se encuentra en los huesos. Es un ion fundamental, entre otras actividades, para la conducción nerviosa y la actividad de los canales de calcio. La hipermagnesemia puede provocar hiporreflexia o alteraciones cardiacas y respiratorias, entre otras. La hipomagnesemia puede provocar debilidad, calambres, temblores, parestesias, fasciculaciones, espasticidad y tetania, así como alteraciones cardiacas y vasculares.
El mayor porcentaje de fósforo corporal se encuentra en forma de cristales de hidroxiapatita en el tejido óseo. La hiperfosfatemia puede favorecer la calcificación ectópica o depósito de sales de calcio en tejidos extraesqueléticos, la aparición de hiperparatiroidismo secundario o la osteodistrofia renal. La hipofosfatemia puede producir debilidad muscular, irritabilidad o disfunción leucocitaria con aumento de las infecciones.

\section{Función hepática}

La medición de las enzimas ${ }^{42}$ que regulan el funcionamiento hepático o la medición de los niveles de proteínas de síntesis hepáticas nos servirán como indicativos de su función. De interés para valorar la función hepática son las transaminasas, la gamma glutamil transferasa (GGT), la fosfatasa alcalina (FA), la lactato deshidrogenasa (LDH) y la bilirrubina, entre otros parámetros. Niveles anormales de albúmina o un tiempo de protrombina elevado reflejarán una alteración en la síntesis hepática de proteínas, y son frecuentes en pacientes con patología hepática crónica.

Las transaminasas ${ }^{43}$, aspartato aminotransferasa/glutamato oxalacetato tansaminasa (ASAT/GOT), y la alanina aminotransferasa/glutamato piruvato transaminasa (ALAT/GPT), se encuentran en altas concentraciones en el hígado, aunque también podemos encontrarlas en el miocardio o el músculo esquelético. Son las Ilamadas enzimas de "citolisis", ya que se ven aumentadas cuando se produce destrucción de las células hepáticas que las contienen. Elevaciones importantes en sus valores nos indicarán patología aguda como hepatitis virales, tóxicas, alcohólicas, isquémicas agudas o tumores hepáti$\cos$. Aumentos moderados en sus niveles pueden encontrarse en casos de esteatosis hepática, consumo elevado de alcohol o hepatitis inducidas por medicamentos, como son el paracetamol o los antifúngicos sistémicos, entre otras condiciones. La ALAT es un marcador más específico de daño hepático que la ASAT. El grado de elevación de las transaminasas no guarda relación con el grado de daño hepático.

$\mathrm{La} \mathrm{FA}^{44}$ es una enzima que se encuentra predominantemente en el hígado y los huesos. Si se elevan los niveles de FA hepática debemos sospechar un cuadro de colestasis (incapacidad para la llegada de bilis desde las células hepáticas hasta el intestino), lo cual requerirá estudios adicionales.

La GGT ${ }^{43}$ es una enzima presente en la membrana plasmática de los hepatocitos, así como en páncreas, conductos biliares o bazo. La elevación de la GGT es un parámetro sensible para la detección de enfermedad hepatobiliar, pero su utilidad clínica es limitada por su falta de especificidad, ya que se puede ver elevada en numerosas condiciones.

La $\mathrm{LDH}^{45}$ es una enzima citoplasmática presente en diferentes tejidos en todo el cuerpo, entre ellos el hígado. Es un parámetro inespecífico para valorar patología hepática. Su mayor utilidad clínica es como marcador de hemolisis.

Una de las patologías más prevalentes en el campo de la podología es la onicomicosis. Existen diferentes líneas de tra- 
tamiento para esta enfermedad, siendo una de ellas la utilización de antifúngicos orales. Diferentes autores han publicado la relación existente entre la utilización de estos tratamientos de manera continuada y el daño hepático ${ }^{46-49}$. La ficha técnica del itraconazol, del ketoconazol, y de la terbinafina publicada por la Agencia Española del Medicamento y Productos Sanitarios recomienda un control de enzimas hepáticas en caso de utilización prologada, y además subraya el potencial efecto hepatotóxico de estos fármacos ${ }^{50-52}$.

De cara a un potencial tratamiento quirúrgico en un paciente con consumo elevado de alcohol, debemos evaluar la función hepática, ya que podría existir alteraciones en la hemostasia. Generalmente se elevan las transaminasas (en mayor proporción la ASAT) y la GGT.

\section{Metabolismo del hierro}

El déficit de hierro (Fe) afecta de manera especial a mujeres en edad fértil, a niños, a la población mayor de 65 años y a individuos en países en vías de desarrollo ${ }^{53}$. Las causas más frecuentes de deficiencia de Fe son una baja ingesta con la dieta, una reducción en su absorción y las pérdidas hemáticas. La deficiencia de hierro se manifiesta principalmente con signos de anemia, intolerancia al ejercicio físico, disnea, cefalea, irritabilidad, fatiga, vértigo, alteraciones en el sueño e incluso alteraciones neurológicas, como el síndrome de piernas inquietas. Se ha establecido relación entre la deficiencia de hierro y la aparición de alteraciones en las uñas, como la coiloniquia ${ }^{54}$.

En la analítica, los valores disminuidos de Fe sérico, por sí mismos, no son diagnósticos de anemia ferropénica o de deficiencia de Fe, por lo que debe ser evaluado en conjunto con la transferrina y ferritina.

\section{Hormonas tiroideas}

La tirotropina (TSH) es una hormona secretada por la hipófisis y que regula la síntesis de hormonas tiroideas triiodotironina (T3) y tiroxina (T4) en la glándula tiroides. La secreción de TSH se regula por un mecanismo de retroalimentación negativo por los niveles de hormonas tiroideas ${ }^{55}$.

Denominamos hipertiroidismo ${ }^{56}$, de manera general, al aumento de hormonas tiroideas libres (T3 y/o T4) en sangre. Causas frecuentes son la enfermedad de Graves, las tiroiditis, el bocio multinodular tóxico, los nódulos tiroideos tóxicos, algunos fármacos, el exceso de yodo y algunos tumores. El hipertiroidismo presenta una serie de manifestaciones clínicas típicas, como son la pérdida de peso, el nerviosismo, la taquicardia, intolerancia al calor, diarrea o temblores. Asimismo, se han descrito una serie de alteraciones neuromusculares como pueden ser la oftalmopatía, parálisis o debilidad muscular, habiéndose referenciado afectación a nivel de los miembros inferiores. Se ha descrito la onicolisis ${ }^{57}$, así como el síndrome de uñas amarillas, asociada al hipertiroidismo. En una analítica nos podemos encontrar diferentes escenarios, pero siempre con el nivel de TSH disminuido.

El hipotiroidismo ${ }^{58}$ se caracteriza por una producción insuficiente de hormonas tiroideas a nivel glandular (hipotiroidismo primario), o bien por una alteración a nivel de la hipófisis que disminuye la producción de TSH (hipotiroidismo secundario). La causa más frecuente de hipotiroidismo primario en nuestro medio es la tiroiditis autoinmune, siendo el déficit de yodo la causa más frecuente a nivel global en el mundo. Clínicamente el hipotiroidismo se caracteriza por un cuadro florido con astenia, letargia, intolerancia al frío, enlentecimiento de funciones intelectuales, aumento de peso, facies hipotiroidea, disminución del apetito, estreñimiento, trastornos menstruales, parestesias, artralgias, alteraciones cutáneas, hiporreflexia, movimientos lentos, edema sin fóvea, bradipsiquia, etc. Se han descrito alteraciones a nivel cutáneo ${ }^{59-61}$ como la queratodermia palmo-plantar, fragilidad ungueal, surcos longitudinales e incluso infecciones por cándidas. En una analítica ${ }^{62}$ tendremos valores de TSH aumentados, y en caso de hipotiroidismo secundario la TSH estará normal o baja.

\section{Ácido úrico}

El aumento de los niveles de ácido úrico en sangre se denomina hiperuricemia, condición generalmente asintomática y que se establece cuando los niveles de urato en sangre son mayores de $7 \mathrm{mg} / \mathrm{dl}$. No debemos confundir la hiperuricemia con la gota ${ }^{63,64}$, la cual representa una entidad clínica producida por depósito de cristales de urato monosódico en diferentes localizaciones. La hiperuricemia es una condición necesaria, pero no suficiente para el diagnóstico de gota. De manera clásica los ataques agudos se manifiestan como una monoartritis aguda, siendo la primera articulación metatarsofalángica ${ }^{65}$ del pie lugar de frecuente asiento (podagra), aunque también pueden afectarse otras articulaciones. En estadios avanzados (gota tofácea) se favorece el depósito de cristales de urato en localizaciones como pabellones auriculares, tendones, bursas o estructuras articulares. En el transcurso de un ataque de gota, en la analítica es frecuente encontrarnos con leucocitosis con predominio de neutrófilos, así como valores de VSG y/o PCR elevados.

\section{Otros}

Los RFA ${ }^{66}$ son aquellas proteínas de síntesis hepática cuyas concentraciones en plasma, en general, aumentan en respuesta a un evento inflamatorio. Cuando se produce un daño que favorece la inflamación, durante la reacción inmunitaria se secretan una serie de citocinas que promueven la síntesis en el hígado de RFA. Entre estas proteínas se encuentran la proteína $C$ reactiva $(P C R)$, la procalcitonina, la haptoglobina, la ferritina o el fibrinógeno. La VSG, aunque no es una proteí- 
na (ver apartado hemograma), se eleva ante eventos inflamatorios. Debe quedar claro que una elevación de los RFA nos debe poner en alerta de una posible causa subyacente, que en un adecuado contexto clínico deberá ser investigado. Valores normales en su determinación no descartan la existencia de patología.

Los marcadores analíticos utilizados en reumatología deben ser utilizados siempre dentro de un contexto clínico. Su positividad o negatividad ayudarán al clínico a confirmar o descartar una determinada patología. Su negatividad no descarta enfermedad.

Tanto los valores de VSG como la PCR se elevan en el contexto de diferentes enfermedades reumáticas. Ambos parámetros son de utilidad para monitorizar la actividad de la enfermedad.

La presencia de factor reumatoide (FR) en un individuo con poliartritis y sintomatología típica de la enfermedad, nos sugiere con alta probabilidad un diagnóstico de $A R^{67}$. Además de valor diagnóstico, el FR también tiene valor pronóstico, ya que su titulación se relaciona con una mayor intensidad en la sintomatología de la enfermedad y con aparición de mayores complicaciones. El FR puede ser positivo en otras enfermedades como el lupus eritematoso sistémico o el síndrome de Sjögren. Se pueden observar niveles de FR elevados en individuos sanos.

Los anticuerpos antipéptidos cíclicos citrulinados ${ }^{68}$ (anti$\mathrm{CCP}$ ) son autoanticuerpos que se dirigen contra proteínas, reconocidas como "extrañas", y por lo tanto provocan una respuesta inmune responsable de la generación de inflamación. Los anti-CCP son positivos en un alto porcentaje de los pacientes con AR. Poseen una muy alta especificidad pero una relativamente baja sensibilidad para el diagnóstico de AR. Los anti-CCP pueden también ser positivos en pacientes con lupus eritematoso sistémico u otras enfermedades del tejido conectivo.

La creatin kinasa ${ }^{69}$ (CK) es una enzima presente en el miocardio, en fibras de músculo esquelético o en el cerebro. Es la enzima más utilizada para el diagnóstico y seguimiento de patologías de origen muscular. La CK también puede ser utilizada como marcador de daño cardiaco.

\section{COAGULACIÓN}

La coagulación es una propiedad intrínseca del plasma sanguíneo, que comienza cuando hay una agresión vascular desencadenándose la llamada "cascada de la coagulación"70. Esta conlleva una serie de reacciones enzimáticas catalizadas por los factores de coagulación (proteínas de síntesis hepática) y algunos iones cuyo punto final es la transformación del fibrinógeno en fibrina y la formación del trombo secundario. La cascada de coagulación de manera tradicional se explica en base a dos vías: la intrínseca y la extrínseca; ambas confluyen en una vía común. En la actualidad se ha puesto en entredicho el modelo clásico de la coagulación, apareciendo el llamado "modelo celular"71, en el que cobra importancia considerar a las propias células como elementos esenciales en el proceso de coagulación.

Es importante tener en cuenta el papel de la vitamina $\mathrm{K}$ como cofactor para la activación de los factores de coagulación. Tal es así, que los anticoagulantes orales (ACO) tradicionales, acenocumarol (Sintrom ${ }^{\circledR}$ ) y la warfarina actúan como antagonistas de la vitamina $\mathrm{K}$, impidiendo la activación de los factores dependientes de ella. La trombina es la proteína encargada de la transformación del fibrinógeno en fibrina y será diana de los nuevos anticoagulantes orales (NACO).

Para medir la eficacia de la coagulación, tenemos diferentes parámetros ${ }^{72,73}$. El tiempo de protrombina (TP) evalúa la vía extrínseca y la vía común de la coagulación y se expresa en segundos. También se puede valorar como ratio (cociente entre el TP del paciente y el TP de referencia obtenido de un individuo sano). Del TP deriva el International Normalized Ratio (INR), parámetro utilizado a nivel internacional para monitorizar y estandarizar el estado de coagulación de pacientes a tratamiento con los ACO tradicionales (Sintrom ${ }^{\circledR}$ ). La utilización de ACO, la deficiencia de vitamina K, la disfunción hepática, las deficiencias congénitas en factores de coagulación, las patologías como la coagulación intravascular diseminada o la presencia de anticuerpos antifosfolípidos pueden aumentar los valores de TP.

El tiempo parcial de tromboplastina activado (TTPA) evalúa la vía intrínseca y la vía común de la coagulación. Es de utilidad para monitorizar aquellos pacientes a tratamiento con heparina no fraccionada (no confundir con la heparina de bajo peso molecular). EI TTPA puede verse alargado en pacientes, por tanto, a tratamiento con heparina, y además en individuos con patología hepática, coagulación intravascular diseminada, enfermedad de Von Willebrand, hemofilia A o B $u$ otras deficiencias en factores de coagulación.

Los valores de coagulación pueden verse alterados por diferentes motivos, pero el más frecuente es la utilización de los $\mathrm{ACO}^{74}$. No existen valores estándar de INR en pacientes a tratamiento con $\mathrm{ACO}$, ya que el rango terapéutico variará en función de las características del paciente y de la patología por la cual está en tratamiento anticoagulante. De manera general, a mayor valor de INR, el paciente tendrá un incremento en el riesgo de sangrado (y menor riesgo tromboembólico). Por otro lado, valores bajos de INR aumentan el riesgo de eventos tromboembólicos (y disminuyen el riesgo de sangrado). Generalmente, antes de una cirugía programada en pacientes a tratamiento con Sintrom ${ }^{\circledR}$ será necesario conocer el valor de INR. Se debe valorar en función del tipo de cirugía y del riesgo tromboembólico el rango aceptable de INR quirúrgico. En la Tabla $\vee$ se indican los valores de referencia de coagulación.

En los últimos años se han desarrollado los NACO ${ }^{75,76}$, los cuales poseen dianas diferentes a los ACO. Son fármacos anticoagulantes inhibidores directos de la trombina (dabigatrán), o inhibidores del factor $X$ activado (rivaroxabán, apixabán y edoxabán), los cuales han sido comercializados con diferentes indicaciones terapéuticas. En la práctica clínica no existe 
Tabla V. Valores de referencia de la coagulación

Coagulación

\begin{tabular}{lcc}
\multicolumn{3}{c}{ Coagulación } \\
\hline & Unidades & Valores de referencia \\
\hline TP & segundos & {$[11.0-15.0]$} \\
\hline TP (actividad) & $\%$ & {$[70.0-120.0]$} \\
\hline TP (ratio) & & {$[0.7-1.3]$} \\
\hline TP (INR) & & {$[0.9-1.5]$} \\
\hline TTPA & segundos & {$[20-40]$} \\
\hline Fibrinógeno & $\mathrm{mg} / \mathrm{dl}$ & {$[150.0-450.0]$} \\
\hline Dímero-D & $\mathrm{ng} / \mathrm{ml}$ & $<100$ \\
\hline
\end{tabular}

ninguna prueba específica de rutina que evalúe la dosis de fármaco en sangre. Tanto el TP como el TTPA en pacientes a tratamiento con NACO se verán prolongados, pero sin existir una correlación entre los valores obtenidos y la dosificación de fármaco en plasma, a diferencia de los pacientes a tratamiento con Sintrom ${ }^{\circledR}$, en los que sí existe relación entre los niveles de INR y la concentración de fármaco en sangre.

La heparina de bajo peso molecular (HBPM) y el fondaparinux ${ }^{77}$ son fármacos anticoagulantes (inhibidores del factor $X$ activado principalmente) de elección tanto para el tratamiento de la enfermedad tromboembólica venosa como para su prevención en pacientes con patología de base o sometidos a determinados tipos de cirugía. Asimismo, ambos fármacos se han venido utilizando como terapia puente en pacientes anticoagulados que van a ser sometidos a cirugía electiva. De manera general, no es necesario monitorizar los niveles de HBPM/fondaparinux, y por lo tanto ni el TP ni la TTPA son parámetros adecuados para valorar el estado de anticoagulación de los pacientes en tratamiento con heparina de bajo peso molecular.
El dímero $D^{78}$ es el producto de la degradación final de la fibrina, y su determinación en plasma es de utilidad en el diagnóstico tanto del embolismo pulmonar como de la trombosis venosa profunda. Un valor negativo en su determinación casi con seguridad excluye el diagnóstico de enfermedad tromboembólica. Por lo tanto, se trata de un parámetro de utilidad para descartar un proceso tromboembólico donde la probabilidad es baja si su valor es normal. En la Tabla VI se indican los puntos clave de este apartado.

\section{ASPECTOS GENERALES DE LA SOLICITUD E INTERPRETACIÓN DE LAS ANALÍTICAS}

Un aspecto que desde hace años preocupa a la comunidad médica y en ámbitos de gestión es la cantidad de pruebas complementarias innecesarias ${ }^{79}$ y redundantes que a diario de manera rutinaria se solicitan en nuestro medio.

Imaginemos una paciente de 35 años, sana, que no toma tratamientos domiciliarios, sin antecedentes médicos de interés, que va a ser sometida a un procedimiento quirúrgico menor en ámbito ambulatorio; ¿tendría sentido solicitar un estudio pre-quirúrgico "rutinario" que incluya una analítica completa, una radiografía de tórax y un electrocardiograma? ¿Esperamos que alguno de los parámetros solicitados resulten alterados y nos obliguen a modificar nuestra conducta? En principio, la respuesta es no.

Otro escenario diferente sería el de un paciente de 75 años, diabético, que desde hace seis se encuentra a tratamiento con anticoagulantes orales (con bastante labilidad en el control de su INR) por una fibrilación auricular, fumador de 1 paquete de cigarrillos al día desde la juventud, que va a ser sometido a la misma intervención que la paciente anterior. ¿Actuaríamos de la misma manera? Siguiendo el sentido común (y las recomendaciones de las guías clínicas como veremos más adelante), este paciente precisará un manejo diferente que la paciente anterior.

\section{Tabla VI. Puntos clave de la coagulación}

- Los dos parámetros de mayor utilidad para evaluar el estado de coagulación de un paciente son el TP y el TTPA

- En pacientes anticoagulados con Sintrom ${ }^{\circledR}$ el INR es el parámetro utilizado para el control de la dosis de fármaco en sangre

- El INR no es un parámetro válido para la monitorización de los NACO

- Los NACO no requieren monitorización analítica de sus niveles

- Tanto el TP como el TTPA se pueden ver alterados por los NACO, pero sus niveles no son indicativos de concentración de fármaco en sangre

- EI TTPA es un parámetro utilizado para el control de las heparinas no fraccionadas

- Tanto las HBPM como el fondaparinux no requieren pruebas de coagulación para su monitorización. Los niveles de TP y el TTPA, por tanto, no son indicativos de su concentración plasmática

TP: tiempo de protrombina. TTPA: tiempo de tromboplastina parcial activado. ACO: anticoagulantes orales. NACO: nuevos anticoagulantes orales. HBPM:

heparina de bajo peso molecular. INR: International Normalized Ratio. 
Sabemos que la solicitud indiscriminada de pruebas, en este caso de laboratorio, genera tanto gastos como riesgos innecesarios a los pacientes ${ }^{79}$. Es un hecho que cuantas más pruebas y parámetros solicitemos, mayor probabilidad de encontrar resultados falsos positivos habrá80, lo cual genera estados de ansiedad a los pacientes, y a su vez genera la necesidad de más pruebas para confirmar o descartar ese "positivo". Debe quedar claro, por tanto, que las pruebas complementarias en general, y las de laboratorio en particular, no deben convertirse en solicitudes "rutinarias" sino que siempre han de ir encaminadas a aclarar una sospecha clínica razonable o para comprobar si, en base a los resultados obtenidos, hemos de modificar nuestra actitud terapéutica, por ejemplo ante una intervención quirúrgica.

¿Qué esperamos cuando solicitamos una prueba de laboratorio? Lo esencial es la obtención de un valor numérico expresado en unas unidades determinadas. Ese valor, lo compararemos con un intervalo de referencia que se considera dentro de la normalidad para, de esa manera, a grandes rasgos, poder catalogar al sujeto como sano o enfermo. Esa "normalidad" se establece en función de diferentes parámetros ${ }^{81}$ (sexo, edad, raza, localización geográfica, etc.) en una población de referencia sana (en este texto hemos utilizado los valores de referencia de población de la provincia de Orense). El intervalo incluirá valores 2 desviaciones estándar por encima y por debajo del valor medio de normalidad. Lo que sobrepase estos valores, por encima o por debajo, será catalogado como valor "anormal". Ahora bien, este rango de normalidad, que se establece en un intervalo del $95 \%$ obtenido a partir de una población de referencia sana, por definición, excluirá a un $5 \%$ de los individuos sanos, los cuales serán catalogados de manera errónea como enfermos, es decir, obteniendo un falso positivo. Por lo tanto, solamente siguiendo las normas básicas de la estadística, en un individuo sano cuantos más parámetros de laboratorio independientes entre sí solicitemos, mayor probabilidad habrá de que aparezcan resultados fuera del rango de normalidad.

Teniendo en cuenta el intervalo de normalidad, debemos reflexionar acerca de su significado. A la hora de interpretar una analítica, es fundamental tener en cuenta el contexto clínico del paciente y no solamente que el parámetro a medir esté fuera de rango. Imaginemos que nuestro laboratorio de referencia establece valores de normalidad para el parámetro "hemoglobina" entre [12-16] g/dl, y nuestra paciente de 35 años nos comenta que en el último examen de salud de su empresa su valor era de $11.5 \mathrm{~g} / \mathrm{dl}$, ¿diagnosticaremos a la paciente de anemia? Si tuviéramos en cuenta el valor de referencia, y entendiendo que un descenso mayor de dos desviaciones estándar del valor medio de hemoglobina se entiende como anemia, en principio sí. Indagando en las analíticas previas de esta paciente vemos que el histórico del valor hemoglobina en los últimos tres años ha estado en 11 , 10.5 , y $11.5 \mathrm{~g} / \mathrm{dl}$ y que según ella se encuentra bien, hace deporte y es una mujer sana. ¿Consideraríamos, por tanto, que dado a que su valor de hemoglobina se encuentra fuera del rango de normalidad tiene anemia? ¿Cancelaríamos su intervención quirúrgica por ello? La respuesta es que no. Una mujer joven, asintomática, con esas cifras de hemoglobina y sin otras alteraciones que demuestren lo contrario, podría ser considerada una mujer sana. Por lo tanto, ha de quedar claro que los resultados de las pruebas analíticas han de ser interpretados dentro de un contexto clínico, y no solamente como datos numéricos.

\section{SOLICITUD DE PRUEBAS ANALÍTICAS EN EL PREOPERATORIO}

La cirugía podológica generalmente se realiza en un ámbito ambulatorio y de manera electiva. De acuerdo con la clasificación ASA (Asociación Americana de Anestesiología), nuestros pacientes mayoritariamente serán clasificados dentro del grupo I y II, es decir, sanos o con enfermedad leve sin repercusión. Aquellos pacientes ASA III o IV, siendo nuestra cirugía electiva, podrán ser diferidos hasta que estén en condiciones de someterse a la intervención. Los procedimientos que se realizan suelen enmarcarse dentro de aquellos en los que no se prevé alto riesgo de sangrado ni necesidad de transfusión. Establecido el contexto, por lo tanto, estamos en la mayor parte de los casos ante pacientes sanos o con enfermedad estable o controlada que van a ser sometidos de manera ambulatoria a intervenciones con bajo riesgo de sangrado.

Diferentes autores y guías clínicas ${ }^{82-87}$ advierten y establecen recomendaciones en contra de la solicitud de pruebas analíticas prequirúrgicas de manera rutinaria, recomendando en su lugar realizar una buena historia clínica en el estudio prequirúrgico, y solicitando aquellas pruebas necesarias individualizando en función de las características del paciente, así como de la intervención. Fundamentan este hecho en la baja probabilidad de que exista alguna enfermedad no diagnosticada que comprometa el periodo perioperatorio en pacientes clínicamente asintomáticos. Además, es de sobra conocido que el valor predictivo de un valor anormal de una prueba de laboratorio en un paciente sano es bajo.

En el año 2009, el Consejo General de Colegios Oficiales de Podólogos publicó una Guía práctica de protocolos quirúrgicos en Podología ${ }^{82}$ con el objetivo de protocolizar la actuación ante procedimientos quirúrgicos en el ámbito de la profesión. En cuanto a la solicitud de analíticas previas a una intervención, recomiendan la solicitud de un perfil analítico "básico" en función de la anamnesis y de la existencia o no de enfermedades sistémicas.

Las guías NICE ${ }^{84}$, publicadas en el año 2016, establecen una serie de recomendaciones generales a la hora de solicitar pruebas de laboratorio prequirúrgicas ante una cirugía electiva (Tablas VII, VIII y IX).

La Sociedad Española de Anestesiología y Reanimación $\left(\right.$ SEDAR) ${ }^{87}$ establece, asimismo, una serie de recomendaciones a la hora de solicitar pruebas de laboratorio en el periodo 
Tabla VII. Recomendaciones solicitud analítica NICE cirugía menor

Cirugía menor

\begin{tabular}{lccc} 
& & Grado ASA & \\
\cline { 2 - 4 } & ASA I & ASA II & ASA III o IV \\
\hline Hemograma & No & No & No \\
\hline Hemostasia & No & No & No \\
\hline Función renal & No & No & Considerar en riesgo de IRA \\
\hline IRA: insuficiencia renal aguda. & & & \\
\hline Cirugía menor: excisión de lesiones cutáneas o drenaje de abscesos. & & \\
\hline
\end{tabular}

Adaptado de Routine preoperative tests for elective surgery: (C NICE (2016) Routine preoperative tests for elective surgery. BJU Int. 2018;121(1):12-6. DOI: 10.1111/bju. 14079.

Tabla VIII. Recomendaciones solicitud analítica NICE cirugía intermedia

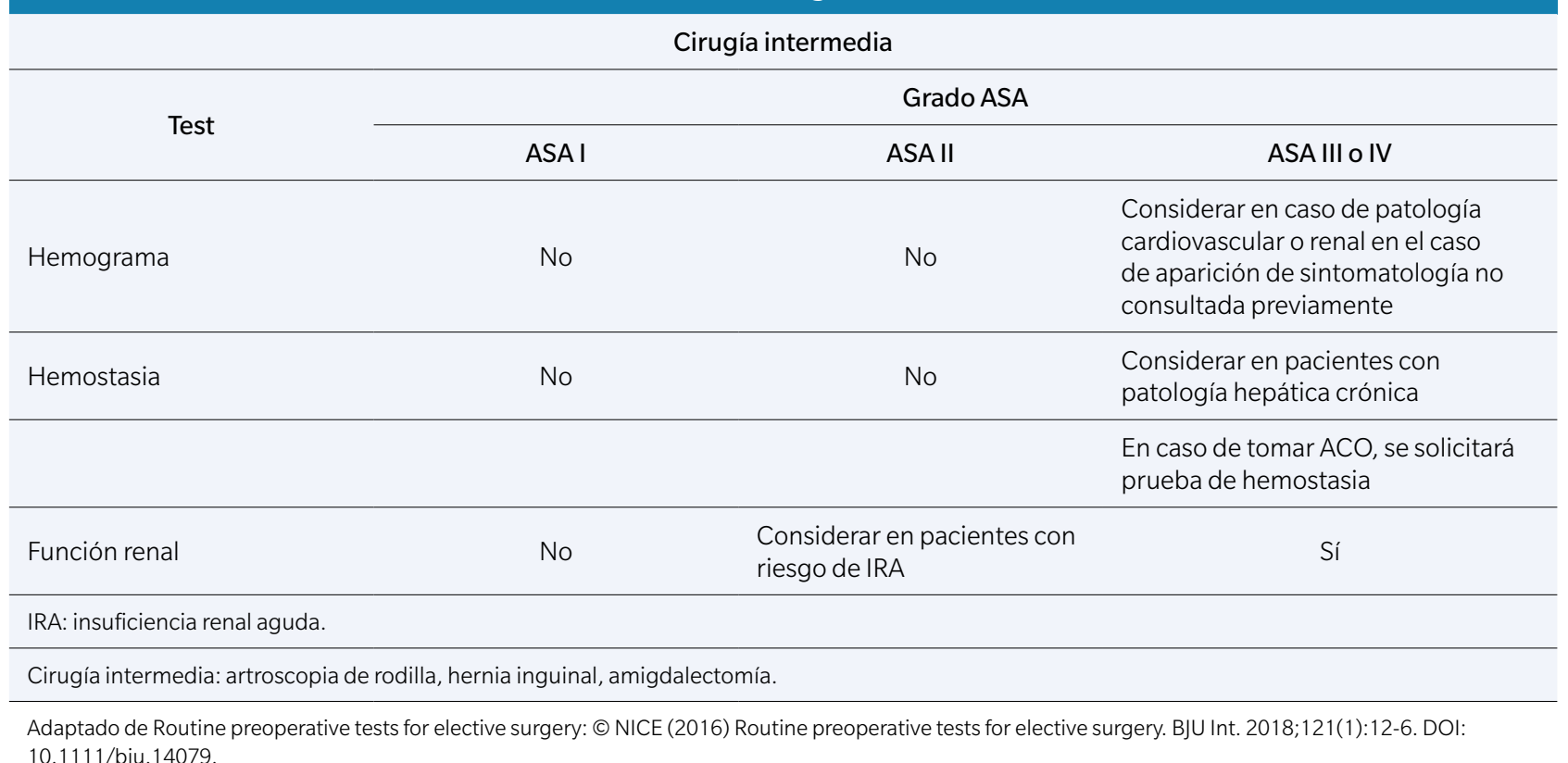

10.1111/bju. 14079.

preoperatorio en pacientes catalogados como ASA I y ASA II que van a ser sometidos a cirugía ambulatoria (Tabla X).

En cuanto al tiempo de validez de las pruebas complementarias, la SEDAR ${ }^{87}$ establece que siempre que no haya cambios en el estado del paciente podrán ser válidas durante, al menos, seis meses para pacientes ASA I y II.

Pese a lo expuesto anteriormente, debemos saber que las sociedades médicas, las guías clínicas y los protocolos establecen solamente recomendaciones en la que los facultativos nos podemos apoyar a la hora de tomar decisiones. Por supuesto existen diferentes condicionantes que pueden hacernos actuar de manera diferente a las recomendaciones. Como facultativos hemos de ser capaces de equilibrar la presión de la medicina defensiva a la hora de solicitar pruebas complementarias, con las necesidades de los pacientes para asegurarnos actuar de acuerdo a la lex artis.

\section{CONCLUSIONES}

La analítica constituye una prueba complementaria utilizada de manera rutinaria en la práctica clínica actual. Su solicitud ha de estar siempre justificada y han de conocerse las diferentes partes en las que se divide, así como los parámetros que se han de solicitar en cada situación clínica.

La utilización de las pruebas analíticas ha de ser racional, teniendo en cuenta tanto el coste económico como las posibles complicaciones derivadas de su realización. Las diferentes socie- 
Tabla IX. Recomendaciones solicitud analítica NICE cirugía mayor/compleja

\section{Cirugía mayor/compleja}

\begin{tabular}{lccc} 
& & Grado ASA & \\
\cline { 2 - 4 } & ASA I & ASA II & ASA III o IV \\
\hline Hemograma & Sí & Sí & Sí \\
\hline Hemostasia & No & No & $\begin{array}{l}\text { Considerar en pacientes con } \\
\text { patología hepática crónica. }\end{array}$ \\
\hline Función renal & & $\begin{array}{l}\text { En caso de tomar ACO, } \\
\text { se solicitará prueba de } \\
\text { hemostasia }\end{array}$ \\
\hline IRA: insuficiencia renal aguda. & $\begin{array}{l}\text { Considerar en pacientes con } \\
\text { riesgo de IRA }\end{array}$ & Sí & Sí \\
\hline Cirugía compleja: troidectomía, cirugía radical de cuello, prótesis articulares completas, prostatectomía. & \\
\hline
\end{tabular}

Adaptado de Routine preoperative tests for elective surgery: (c) NICE (2016) Routine preoperative tests for elective surgery. BJU Int. 2018;121(1):12-6. DOI: $10.1111 /$ bju. 14079

\section{Tabla X. Recomendaciones solicitud analítica} SEDAR

Cirugía ambulatoria en pacientes ASA I y ASA II

\begin{tabular}{|c|c|}
\hline \multicolumn{2}{|c|}{ Hemoglobina y hematocrito } \\
\hline ASAI & No recomendado \\
\hline \multirow{4}{*}{ ASA II } & Antecedentes de anemia o hemorragia reciente \\
\hline & Enfermedad hepática o renal \\
\hline & Enfermedad coronaria estable \\
\hline & $\begin{array}{l}\text { Mayores de } 80 \text { años con enfermedad } \\
\text { cardiovascular y/o respiratoria }\end{array}$ \\
\hline \multicolumn{2}{|c|}{ Electrolitos y creatinina } \\
\hline \multirow{3}{*}{ ASA IY II } & $\begin{array}{l}\text { Considerar si se van a utilizar contrastes } \\
\text { iodados }\end{array}$ \\
\hline & $\begin{array}{l}\text { Considerar si está tomando fármacos que } \\
\text { puedan afectar sus niveles }\end{array}$ \\
\hline & Considerar si el paciente toma digoxina \\
\hline \multicolumn{2}{|c|}{ Coagulación } \\
\hline ASA IY II & No se recomienda \\
\hline
\end{tabular}

Adaptado de Zaballos M, López-Álvarez S, Argente P, López A; Grupo de Trabajo de Pruebas Preoperatorias. Preoperative tests recommendations in adult patients for ambulatory surgery. Rev Esp Anestesiol Reanim. 2015;62(1):29-41. DOI: 10.1016/j.redar.2014.07.007.

dades científicas, así como los servicios o unidades, establecen recomendaciones a través de sus propias guías clínicas o protocolos. La decisión del facultativo en base al tipo de paciente, a la sospecha diagnóstica o a la intervención quirúrgica a la que se va a someter ha de equilibrarse con dichas recomendaciones.

\section{BIBLIOGRAFÍA}

1. Bârsu C. History of Medicine between tradition and modernity. Clujul Med. 2017;90(2):243-5. DOI: 10.15386/cjmed-794.

2. Zier BG. Utility of diagnostic blood tests in clinical podiatric medicine. J Am Podiatr Med Assoc. 2015; 105(1):61-73. DOI: 10.7547/8750-7315105.1.61.

3. Rupp M, Frauenhoffer S. Preoperative laboratory testing and podiatric surgery. J Foot Surg. 1987;26(6):493-5.

4. Harris EJ. Usefulness of preoperative testing in pediatric podiatric surgery. Does it influence clinical decisions? Clin Podiatr Med Surg. 1997;14(1):149-78.

5. Skully R, Beasley CA, Lutz KW. Current trends in preoperative patient evaluation and management for podiatric surgeons. Clin Podiatr Med Surg. 2003;20(2):213-35, vii.

6. Crausman RS, Glod DJ. Perioperative medical assessment of the podiatric surgical patient. J Am Podiatr Med Assoc. 2004;94(2):86-9.

7. Kaczander BI, Cramblett JG, Mann GS. Perioperative management of the podiatric surgical patient. Clin Podiatr Med Surg. 2007;24(2):22344.

8. Vinay K, Abbas AK, Aster JC. Robbins and Cotran Pathologic Basis of Disease. Ninth edition. Philadelphia, PA: Elsevier/Saunders; 2015.

9. Harrison T, Kasper D. Harrison's principles of internal medicine. New York: McGraw-Hill Medical Publ. Division; 2015.

10. Rozman C, Cardellach López F, Domarus A, Farreras Valentí P. Medicina interna. Barcelona: Elsevier; 2016.

11. Torrens M. Cell Blood Count. Clinical Interpretation. Rev Med Clin Condes. 2015;26(6):713-25.

12. Beutler E, Waalen J. The definition of anemia: what is the lower limit of normal of the blood hemoglobin concentration? Blood. 2006;107(5):1747-50.

13. Cascio MJ, DeLoughery TG. Anemia: Evaluation and Diagnostic Tests. Med Clin North Am. 2017;101(2):263-84. DOI: 10.1016/j. mcna.2016.09.003.

14. Schrier L, Mentzer W, Tirnauer J. Approach to the adult with anemia. Post TW, ed. UpToDate. Waltham, MA: UpToDate Inc. https://www. uptodate.com (Acceso el 14 de enero de 2019).

15. Camaschella C. Iron-deficiency anemia. N Engl J Med. 2015;372(19):1832-43. DOI: 10.1056/NEJMra1401038.

16. Madu AJ, Ughasoro MD. Anaemia of Chronic Disease: An In-Depth Review. Med Princ Pract. 2017;26(1):1-9. DOI: 10.1159/000452104. 
17. Green R, Datta Mitra A. Megaloblastic Anemias: Nutritional and Other Causes. Med Clin North Am. 2017r;101(2):297-317. DOI: 10.1016/j. mcna.2016.09.013.

18. Cho JH, Suh JD, Kim JK, Hong SC, Park IH, Lee HM. Correlation between skin-prick testing, individual specific IgE tests, and a multiallergen lgE assay for allergy detection in patients with chronic rhinitis. Am J Rhinol Allergy. 2014;28(5):388-91. DOI: 10.2500/ajra.2014.28.4074.

19. Freson K, Wijgaerts A, van Geet C. Update on the causes of platelet disorders and functional consequences. Int J Lab Hematol. 2014;36(3):313-25. DOI: 10.1111/ijlh. 12213.

20. Lordkipanidzé M. Platelet Function Tests. Semin Thromb Hemost. 2016;42(3):258-67. DOI: 10.1055/s-0035-1564834.

21. Arrieta-Blanco JJ, Bartolomé-Villar B, Juzgado A, Mourelle-Martínez R. Assessment of PFA-100 system for the measurement of bleeding time in oral surgery. Med Oral Patol Oral Cir Bucal. 2006;11:E514-9.

22. Singal A, Arora R. Nail as a window of systemic diseases. Indian Dermatol Online J. 2015;6(2):67-74. DOI: 10.4103/2229-5178.153002.

23. Fawcett RS, Linford S, Stulberg DL. Nail abnormalities: clues to systemic disease. Am Fam Physician. 2004;69(6):1417-24.

24. Zaiac MN, Walker A. Nail abnormalities associated with systemic pathologies. Clin Dermatol. 2013;31(5):627-49. DOI: 10.1016/j.clindermatol.2013.06.018.

25. Herzberg AJ. Nail manifestations of systemic diseases. Clin Podiatr Med Surg. 1995;12(2):309-18.

26. American Diabetes Association. (2) Classification and diagnosis of diabetes. Diabetes Care. 2015;38 Suppl:S8-S16. DOI: 10.2337/dc15-S005.

27. Ohde S, Deshpande GA, Yokomichi H, Takahashi O, Fukui T, Yamagata Z. HbA1c monitoring interval in patients on treatment for stable type 2 diabetes. A ten-year retrospective, open cohort study. Diabetes Res Clin Pract. 2018;135:166-71. DOI: 10.1016/j.diabres.2017.11.013.

28. NICE. Type 2 diabetes in adults: management; 2017. https:// www. nice.org.uk/guidance/ng28/chapter/1- recommendations. [accessed January 26, 2019].

29. Fernandez-Prado R, Castillo-Rodriguez E, Velez-Arribas FJ, Gracia-Iguacel C, Ortiz A. Creatinine Clearance Is Not Equal to Glomerular Filtration Rate and Cockcroft-Gault Equation Is Not Equal to CKD-EPI Collaboration Equation. Am J Med. 2016 ;129(12):1259-63. DOI: 10.1016/j. amjmed.2016.08.019.

30. Levey AS, James MT. Acute Kidney Injury. Ann Intern Med. 2017;167(9):ITC66-ITC80. DOI: 10.7326/AITC201711070.

31. Webster AC, Nagler EV, Morton RL, Masson P. Chronic Kidney Disease. Lancet. 2017;389(10075):1238-52. DOI: 10.1016/S01406736(16)32064-5.

32. Kaminski MR, Raspovic A, McMahon LP, Strippoli GF, Palmer SC, Ruospo $M$, et al. Risk factors for foot ulceration and lower extremity amputation in adults with end-stage renal disease on dialysis: a systematic review and meta-analysis. Nephrol Dial Transplant. 2015;30(10):1747-66. DOI: 10.1093/ndt/gfv114.

33. Luchetti TJ, Chung A, Olmscheid N, BohI DD, Hustedt JW. Hypoalbuminemia Is Associated With Increased Postoperative Mortality and Complications in Hand Surgery. Hand (N Y). 2019:1558944718820959. DOI: 10.1177/1558944718820959 [Epub ahead of print].

34. Meyer CP, Rios-Diaz AJ, Dalela D, Ravi P, Sood A, Hanske J, et al. The association of hypoalbuminemia with early perioperative outcomes A comprehensive assessment across 16 major procedures. Am J Surg. 2017;214(5):871-83. DOI: 10.1016/j.amjsurg.2016.11.023.

35. Tavares NT, Costa A, Damasceno M. Muehrcke's lines. Autops Case Rep. 2018;8(1):e2018014. DOI: 10.4322/acr.2018.014

36. Williams V, Jayashree M. Muehrcke Lines in an Infant. J Pediatr. 2017;189:234. DOI: 10.1016/j.jpeds.2017.05.039.

37. Ates Bulut E, Soysal P, Aydin AE, Dokuzlar O, Kocyigit SE, Isik AT. Vitamin B12 deficiency might be related to sarcopenia in older adults. Exp Gerontol. 2017;95:136-140. DOI: 10.1016/j.exger.2017.05.017.

38. Oberlin BS, Tangney CC, Gustashaw KA, Rasmussen HE. Vitamin B12 deficiency in relation to functional disabilities. Nutrients. 2013;5(11):4462-75. DOI: 10.3390/nu5114462.

39. Koike H, Takahashi M, Ohyama K, Hashimoto R, Kawagashira Y, lijima M, et al. Clinicopathologic features of folate-deficiency neuropathy. Neurology. 2015;84(10):1026-33. DOI: 10.1212/WNL.0000000000001343.
40. Abdul Kadir L, Stacey M, Barrett-Jolley R. Emerging Roles of the Membrane Potential: Action Beyond the Action Potential. Front Physiol. 2018;9:1661. DOI: 10.3389/fphys.2018.01661.

41. Rittenhouse KJ, To T, Rogers A, Wu D, Horst M, Edavettal M, et al. Hyponatremia as a fall predictor in a geriatric trauma population. Injury. 2015;46(1):119-23. DOI: 10.1016/j.injury.2014.06.013.

42. McGill MR. The past and present of serum aminotransferases and the future of liver injury biomarkers. EXCLI J. 2016;15:817-28. DOI: 10.17179/excli2016-800.

43. Lala V, Minter DA. Liver Function Tests. 2018 Oct 27. StatPearls [Internet]. Treasure Island (FL): StatPearls Publishing; 2018 Jan-. Available from http://www.ncbi.nlm.nih.gov/books/NBK482489/ PubMed PMID: 29494096.

44. Lowe D, John S. Alkaline Phosphatase. 2018 Oct 27. StatPearls [Internet]. Treasure Island (FL): StatPearls Publishing; 2018. Available from http://www.ncbi.nlm.nih.gov/books/NBK459201/ PubMed PMID: 29083622.

45. Faloppi L, Bianconi M, Memeo R, Casadei Gardini A, Giampieri R, Bittoni A, et al. Lactate Dehydrogenase in Hepatocellular Carcinoma: Something Old, Something New. Biomed Res Int. 2016;2016:7196280. DOI: 10.1155/2016/7196280.

46. Chang $\mathrm{CH}$, Young-XuY, Kurth T, Orav JE, Chan AK. The safety of oral antifungal treatments for superficial dermatophytosis and onychomycosis: a meta-analysis. Am J Med. 2007;120(9):791-8.

47. Greenblatt HK, Greenblatt DJ. Liver injury associated with ketoconazole: review of the published evidence. J Clin Pharmacol. 2014;54(12):1321 9. DOI: $10.1002 / \mathrm{jcph} .400$

48. Lo Re V $3^{\text {rd }}$, Carbonari DM, Lewis JD, Forde KA, Goldberg DS, Reddy KR, et al. Oral Azole Antifungal Medications and Risk of Acute Liver Injury, Overall and by Chronic Liver Disease Status. Am J Med. 2016;129(3):283-91.e5. DOI: 10.1016/j.amjmed.2015.10.029.

49. Kramer ON, Albrecht J. Clinical presentation of terbinafine-induced severe liver injury and the value of laboratory monitoring: a Critically Appraised Topic. Br J Dermatol. 2017;177(5):1279-84. DOI: 10.1111/ bjd. 15854 .

50. Asociación Española del Medicamento y Productos Sanitarios [Sede Web] *. Madrid. [acceso 27 de enero de 2019]. Disponible en: https:// cima.aemps.es/cima/pdfs/es/ft/65775/65775_ft.pdf.

51. Asociación Española del Medicamento y Productos Sanitarios [Sede Web] *. Madrid. [acceso 27 de enero de 2019]. Disponible en: https:// cima.aemps.es//cima/pdfs/es/p/56341/56341_p.pdf.

52. Asociación Española del Medicamento y Productos Sanitarios [Sede Web] *. Madrid. [acceso 27 de enero de 2019]. Disponible en: http:// cima.aemps.es/cima/pdfs/es/ft/68131/68131_ft.pdf.

53. Camaschella $\mathrm{C}$. Iron deficiency: new insights into diagnosis and treatment. Hematology Am Soc Hematol Educ Program. 2015;2015:8-13. DOI: 10.1182/asheducation-2015.1.8

54. Ghaffari S, Pourafkari L. Koilonychia in Iron-Deficiency Anemia. N Engl J Med. 2018;379(9):e13. DOI: 10.1056/NEJMicm 1802104.

55. Mullur R, Liu YY, Brent GA. Thyroid hormone regulation of metabolism. Physiol Rev. 2014;94(2):355-82. DOI: 10.1152/physrev.00030.2013.

56. De Leo S, Lee SY, Braverman LE. Hyperthyroidism. Lancet. 2016;388(10047):906-18. DOI: 10.1016/S0140-6736(16)00278-6.

57. Razi A, Golforoushan F, Nejad AB, Goldust M. Evaluation of dermal symptoms in hypothyroidism and hyperthyroidism. Pak J Biol Sci. 2013;16(11):541-4.

58. Chaker L, Bianco AC, Jonklaas J, Peeters RP. Hypothyroidism. Lancet. 2017;390(10101):1550-62. DOI: 10.1016/S0140-6736(17)30703-1.

59. Taguchi T. Brittle Nails and Hair Loss in Hypothyroidism. N Engl J Med. 2018;379(14):1363. DOI: 10.1056/NEJMicm1801633.

60. Mizutani Y, Ito M, Takahashi T, Seishima M. Acquired palmoplantar keratoderma associated with hypothyroidism. J Dermatol. 2016;43(10):1246-7. DOI: 10.1111/1346-8138.13363.

61. Takasu N, Seki H. Plummer's Nails (Onycholysis) in a Thyroid-stimulation-blocking Antibody (TSBAb)-positive Patient with Hypothyroidism. Intern Med. 2018;57(20):3055-6. DOI: 10.2169/internalmedicine.0809-18. 
62. Ross DS, Cooper DS, Mulder JE. Laboratory assessment of thyroid function. Post TW, ed. UpToDate. Waltham, MA: UpToDate Inc. https://www. uptodate.com (Acceso el 27 de enero de 2019).

63. Vargas-Santos AB, Taylor WJ, Neogi T. Gout Classification Criteria: Update and Implications. Curr Rheumatol Rep. 2016;18(7):46.

64. Bardin T, Richette P. Impact of comorbidities on gout and hyperuricaemia: an update on prevalence and treatment options. BMC Med. 2017;15(1):123. DOI: 10.1186/s12916-017-0890-9.

65. Stewart S, Dalbeth N, Vandal AC, Rome K. The first metatarsophalangeal joint in gout: a systematic review and meta-analysis. BMC Musculoskelet Disord. 2016;17:69.

66. Kushner I, Furst D, Romain P. Acute Phase Reactants. Post TW, ed. UpToDate. Waltham, MA: UpToDate Inc. https://www.uptodate.com (Acceso el 12 de enero de 2019).

67. Gavrilă BI, Ciofu C, Stoica V. Biomarkers in Rheumatoid Arthritis, what is new? J Med Life. 2016;9(2):144-8.

68. Sun J, Zhang Y, Liu L, Liu G. Diagnostic accuracy of combined tests of anti cyclic citrullinated peptide antibody and rheumatoid factor for rheumatoid arthritis: a meta-analysis. Clin Exp Rheumatol. 2014;32(1):11-21.

69. Moghadam-Kia S, Oddis CV, Aggarwal R. Approach to asymptomatic creatine kinase elevation. Cleve Clin J Med. 2016;83(1):37-42. DOI: 10.3949/ccjm.83a.14120.

70. Smith SA, Travers RJ, Morrissey JH. How it all starts: Initiation of the clotting cascade. Crit Rev Biochem Mol Biol. 2015;50(4):326-36. DOI: 10.3109/10409238.2015.1050550.

71. Ho KM, Pavey W. Applying the cell-based coagulation model in the management of critical bleeding. Anaesth Intensive Care. 2017;45(2):166-76.

72. Levy JH, Szlam F, Wolberg AS, Winkler A. Clinical use of the activated partial thromboplastin time and prothrombin time for screening: a review of the literature and current guidelines for testing. Clin Lab Med. 2014;34(3):453-77. DOI: 10.1016/j.cll.2014.06.005.

73. Zehnder J, Leung L, Tirnauer J. Clinical use of coagulation tests. Post TW, ed. UpToDate. Waltham, MA: UpToDate Inc. https://www.uptodate.com (acceso el 15 de enero de 2019).

74. López-LópezJA, Sterne JAC, Thom HHZ, Higgins JPT, Hingorani AD, Okoli $\mathrm{GN}$, et al. Oral anticoagulants for prevention of stroke in atrial fibrillation: systematic review, network meta-analysis, and cost effectiveness analysis. BMJ. 2017 Nov 28;359:j5058. DOI: 10.1136/bmj.j5058. Erratum in: BMJ. 2017 Dec 4;359:j5631. Erratum in: BMJ. 2018;361:k2295.

75. Fenger-Eriksen C, Münster AM, Grove EL. New oral anticoagulants: clinical indications, monitoring and treatment of acute bleeding complications. Acta Anaesthesiol Scand. 2014;58(6):651-9. DOI: 10.1111/aas. 12319.
76. Leung L, Manucci P, Tirnauer J. Direct oral anticoagulants and parenteral direct thrombin inhibitors: Dosing and adverse effects. Post TW, ed. UpToDate. Waltham, MA: UpToDate Inc. https://www.uptodate.com (acceso el 16 de enero de 2019).

77. Babin JL, Traylor KL, Witt DM. Laboratory Monitoring of Low-Molecular-Weight Heparin and Fondaparinux. Semin Thromb Hemost. 2017;43(3):261-9. DOI: 10.1055/s-0036-1581129.

78. Berraondo Fraile J, Juan Samper G, Fernández-Fabrellas E, Konishi I, López Vazquéz A, Bediaga Collado A, et al. [D-dimer testing in the emergency department: age adjustment, inappropriate use, and ability to predict the extension and severity of pulmonary embolism]. Emergencias. 2016;28(4):223-8.

79. Benítez-Arvizu G, Novelo-Garza B, Mendoza-Valdez AL, Galván-Cervantes J, Morales-Rojas A. Excessive spending by misuse of clinical laboratory. Rev Med Inst Mex Seguro Soc. 2016;54 Suppl 2:S216-23.

80. Rodríguez-Borja E, Corchon-Peyrallo A, Aguilar-Aguilar G, Carratala-Calvo A. Utility of routine laboratory preoperative tests based on previous results: Time to give up. Biochem Med (Zagreb). 2017;27(3):030902. DOI: 10.11613/BM.2017.030902.

81. Daly CH, Higgins V, Adeli K, Grey VL, Hamid JS. Reference interval estimation: Methodological comparison using extensive simulations and empirical data. Clin Biochem. 2017;50(18):1145-58. DOI: 10.1016/j. clinbiochem.2017.07.005.

82. Guía práctica de protocolos quirúrgicos en podología. Consejo General de Colegios Oficiales de Podólogos. 2009. Madrid.

83. National Guideline Centre (UK). Preoperative Tests (Update): Routine Preoperative Tests for Elective Surgery. London: National Institute for Health and Care Excellence (UK); 2016 Apr.

84. Routine preoperative tests for elective surgery: (c) NICE (2016) Routine preoperative tests for elective surgery. BJU Int. 2018;121(1):12-6. DOI: 10.1111/bju.14079.

85. Phoenix GK, Elliott T, Chan JK, Das SK. Preoperative blood tests in elective general surgery: cost and clinical implications. J Perioper Pract. 2012;22(9):282-8.

86. Sigmund AE, Stevens ER, Blitz JD, Ladapo JA. Use of Preoperative Testing and Physicians' Response to Professional Society Guidance. JAMA Intern Med. 2015;175(8):1352-9. DOI: 10.1001/jamainternmed.2015.2081.

87. Zaballos M, López-Álvarez S, Argente P, López A; Grupo de Trabajo de Pruebas Preoperatorias. [Preoperative tests recommendations in adult patients for ambulatory surgery]. Rev Esp Anestesiol Reanim. 2015;62(1):29-41. DOI: 10.1016/j.redar.2014.07.007. 